\title{
Overcoming barriers in access to ophthalmic education with virtual learning
}

\author{
Bonnie He $\mathbb{I}^{1} \cdot$ Stuti M. Tanya ${ }^{2} \cdot$ Sanjay Sharma ${ }^{3}$
}

Received: 16 November 2020 / Revised: 19 November 2020 / Accepted: 23 November 2020 / Published online: 15 December 2020

(c) The Author(s), under exclusive licence to Springer Nature Limited part of Springer Nature 2020

\section{To the Editor:}

We would like to congratulate Dr Chatziralli et al. for their thought-provoking study on virtual education for ophthalmology during COVID-19. In this cross-sectional survey study, Dr Chatziralli and her team found a significant increase in the use of e-learning alternatives during the pandemic [1]. Medical training relies on the continued succession of learners, and as such, there is a critical need to minimize disruptions in this process to avoid negative downstream sequelae. Thus, learners and educators alike are reimagining contemporary medical education with a "forward thinking and scholarly approach" in adopting virtual pedagogies for acquiring clinical knowledge and skills [2].

Recently, we conducted a study to assess the efficacy of interactive virtual ophthalmology education for medical students during COVID-19. We found that interactive webinars and modules can successfully recreate clinically immersive learning environments while maintaining social distancing. Furthermore, we found that such open-access virtual platforms may mitigate inequities in accessing high-quality medical education and also reduce feelings of social isolation among learners [3]. Our findings are applicable beyond the context of COVID-19—globally, medical students report not gaining sufficient exposure to ophthalmology through formal

These authors contributed equally: Bonnie He, Stuti M. Tanya

Sanjay Sharma

drsharma@insidermedicine.com

1 Faculty of Medicine, University of British Columbia, Vancouver, BC, Canada

2 Faculty of Medicine, Memorial University of Newfoundland, St. John's, NL, Canada

3 Department of Ophthalmology, Queen's University, Kingston, ON, Canada medical education, and virtual learning may help to bridge this gap.

Moreover, the authors argue that a "significant and inescapable disadvantage of the shift online is the restriction of professional networking and opportunities for 'in person' collaboration." [1] Of course, this has implications for personal and professional development among the next generation of physicians [4]. Medical students already comprise one of the world's loneliest populations, and early reports suggest that the mental health effects of social distancing and the colloquially termed "Zoom fatigue" may be deepening feelings of isolation in this group [5].

COVID-19 has catapulted us into a future defined by virtually integrated medical education. How we choose to move forward in this paradigm may redefine what it means to be a medical student, doctor, and lifelong learner forever. Future studies should investigate the impact of this shift toward virtual learning on metrics of learner well-being and professional identity formation as well as a more nuanced understanding of how to best deliver medical education in a virtual setting.

Funding This research did not receive any specific grant from funding agencies in the public, commercial, or not-for-profit sectors.

\section{Compliance with ethical standards}

Conflict of interest SS: Founder and Editor-In-Chief of MEDSKL. BH: None. ST: None.

Publisher's note Springer Nature remains neutral with regard to jurisdictional claims in published maps and institutional affiliations.

\section{References}

1. Chatziralli I, Ventura CV, Touhami S, Reynold R, Nassisi M, Weinberg T, et al. Transforming ophthalmic education into virtual learning during COVID-19 pandemic: a global perspective. Eye. 2020. https://doi.org/10.1038/s41433-020-1080-0. 
2. Rose S. Medical Student Education in the Time of COVID19. JAMA. 2020;323:2131-2. https://doi.org/10.1001/jama.2020. 5227.

3. He B, Tanya S, Sharma S. Perspectives on virtual ophthalmology education among Canadian medical students. Can J Ophthalmol. Journal Canadien D'ophtalmologie. 2020 Oct. https://doi.org/10. 1016/j.jcjo.2020.09.021.
4. Lucey CR, Johnston SC. The Transformational Effects of COVID19 on Medical Education. JAMA. 2020;324:1033-4. https://doi. org/10.1001/jama.2020.14136.

5. Dyrbye LN, West CP, Satele D, Boone S, Tan L, Sloan J, et al. Burnout among U.S. medical students, residents, and early career physicians relative to the general U.S. population. Acad Med. 2014;89 (Mar):443-51. https://doi.org/10.1097/ACM.0000000000000134. 